\title{
Um Estudo com Egressos do Curso de Fisioterapia da Universidade Federal de Minas Gerais (UFMG) - 1982-2005
}

\section{- Fisioterapia. \\ - Avaliação. \\ - Currículo.}

PALAVRAS-CHAVE

\section{KEYWORDS}

- Physical Therapy Specialty.

- Evaluation.

- Curriculum

Recebido em: 01/04/2010

Aprovado em: 06/07/2010

REVISTA BRASLLERA DE EDUCAÇÃO MÉDICA
A Study on Alumni from the Undergraduate
Course in Physical Therapy at the Federal
University in Minas Gerais (UFMG) - 1982-2005

Ana Maria Chagas Sette Câmara Lucíola Licínio de Castro Paixão Santos ${ }^{I}$

\begin{abstract}
RESUMO
Estudo com egressos do curso de graduação em Fisioterapia da UFMG entre 1982 e 2005. Analisou-se a percepção dos egressos sobre o curso, bem como de seus percursos profissionais e as relações que podem ser estabelecidas entre ambos. Foi realizado um estudo transversal com questionário autoaplicável em egressos selecionados pelo método de amostragem estratificada, abordando os seguintes aspectos: identificação e contatos; estudos após a graduação; atividades profissionais; mercado de trabalho; avaliação do curso de graduação. Estudos no campo da sociologia das profissões e na área de currículo fundamentam este trabalho e constituem a referência para a análise dos dados. Segundo os resultados obtidos, o curso não só alcançou seu objetivo inicial de atender à demanda de formar profissionais para atuar na reabilitação, como teve importante participação na construção da identidade da profissão em Minas Gerais, tendo impacto na representação interna e externa ao grupo, ampliando e delimitando fronteiras do campo de atuação. Constata-se que é um curso de práticas pedagógicas tradicionais, com inserção tardia nos cenários de prática. Os dados mostram, ainda, que o egresso está inserido no mercado de trabalho, satisfeito com sua atividade profissional e reconhece que introduz novas técnicas e formas de atuação no mercado de trabalho. Praticamente todos os egressos estão em atividades relacionadas com a fisioterapia e avaliam que vale a pena ser fisioterapeuta. Os dados sugerem também que as possibilidades de trabalho para os graduados em Fisioterapia pela UFMG são bastante amplas.
\end{abstract}

\begin{abstract}
This was a study on alumni from the undergraduate course in physical therapy at the Federal University in Minas Gerais (UFMG) from 1982 to 2005. The study analyzed graduates' perceptions of the course, as well as their professional careers and the relations between the two. A cross-sectional study was conducted with a questionnaire answered by selected alumni, using a stratified sampling method and covering the following: personal identification and contact information; graduate studies; professional activities; work market; and evaluation of the undergraduate course. Research in the field of sociology of the professions and the curriculum provided the basis for this study and the reference for the data analysis. According to the findings, the course not only achieved its initial objective of meeting the demand for training professionals to work in rehabilitation, but made an important contribution to the establishment of the profession's identity in the State of Minas Gerais, with an impact on the group's internal and external representation, expanding and demarcating borders in its field of activity. The course involves traditional teaching practices, with late inclusion in physical therapy practice settings. The data further show that the alumni are participating in their work market and satisfied with their professional activity, besides recognizing that the course introduced new techniques and ways of acting in the work market. Virtually all of the alumni are involved in activities related to physical therapy and believe it is worthwhile to be a physical therapist. The data also suggest ample work possibilities for graduates of the UFMG School of Physical Therapy.
\end{abstract}




\section{INTRODUÇÃO}

A avaliação institucional constitui um campo em expansão no Brasil, considerando-se o crescente interesse em sistematizar a avaliação como meio de monitoramento e implementação de políticas no ensino superior. É também considerada uma prática que possibilita a transparência das realizações institucionais tanto para a comunidade universitária como para a sociedade. A avaliação deve possibilitar, à comunidade acadêmica, analisar os processos contraditórios que permeiam a vida universitária e procurar dar uma dinâmica ao processo de avaliação que contemple uma visão de totalidade da problemática educacional $^{1}$.

Entre as diferentes possibilidades de avaliação dos cursos universitários, registra-se a alternativa de avaliar a partir da percepção do egresso, quando já exercendo atividades profissionais. Em seu cotidiano de trabalho, o egresso enfrenta situações complexas, que o levam a confrontar as competências desenvolvidas durante o curso com as requeridas no exercício profissional. Pode-se, a partir daí, avaliar a adequação de estrutura pedagógica do curso que foi vivenciado, bem como aspectos intervenientes no processo de formação acadêmica ${ }^{2}$.

Este estudo foi desenvolvido como requisito parcial para a obtenção do título de Mestre em Educação no Programa de Pós-Graduação em Educação: Conhecimento e Inclusão Social, da Faculdade de Educação da UFMG, em 2006³. O foco central deste estudo foi analisar o processo de formação profissional do fisioterapeuta na UFMG e sua inserção no mercado de trabalho a partir da percepção dos egressos, considerando seu tipo de atuação profissional e seus investimentos no aprimoramento profissional. Os resultados obtidos neste estudo têm contribuído no processo de reforma curricular e no aprofundamento das discussões sobre o processo de formação e profissionalização do fisioterapeuta formado na UFMG.

\section{MÉTODO}

Para identificar e analisar a avaliação que os egressos do curso de graduação em Fisioterapia da UFMG fazem dele, bem como de seus percursos profissionais e das relações que possam ser estabelecidas entre ambos, optou-se por um estudo transversal com questionário autoaplicável em egressos selecionados pelo método de amostragem estratificada ${ }^{4}$.

O curso de graduação em Fisioterapia da UFMG possuía, até janeiro de 2005, uma população total de 44 turmas formadas, num total de 828 ex-alunos. Considerando o processo histórico do curso na UFMG, essa população foi dividida em três estratos para facilitar a análise das respostas desses egressos de acordo com o contexto curricular do curso: a criação (03/12/82 até $20 / 07 / 90)$, a reestruturação $(21 / 12 / 90$ até $18 / 12 / 97)$ e o amadurecimento do curso (24/07/98 até 21/01/05). Dessa forma, para a população total de 828 egressos, o tamanho total da amostra calculada neste estudo foi de 91 egressos, sendo 25 do Estrato 1, 33 do Estrato 2 e 33 do Estrato 3 (Tabela 1).

TABELA 1

População, Amostra e Estratos

\begin{tabular}{|c|c|c|c|c|}
\hline & $\begin{array}{c}\text { Estrato } 1 \\
\text { Egressos } \\
\text { graduados de } \\
03 / 12 / 82 \text { a } \\
20 / 07 / 90\end{array}$ & $\begin{array}{c}\text { Estrato } 2 \\
\text { Egressos } \\
\text { graduados de } \\
21 / 12 / 90 \text { a } \\
18 / 12 / 97\end{array}$ & $\begin{array}{c}\text { Estrato } 3 \\
\text { Egressos } \\
\text { graduados de } \\
24 / 07 / 98 \text { a } \\
21 / 01 / 05\end{array}$ & Total \\
\hline Universo & 241 & 287 & 300 & 828 \\
\hline $\begin{array}{l}\text { Sorteados + } \\
\text { reservas }\end{array}$ & 37 & 45 & 48 & 130 \\
\hline $\begin{array}{l}\text { Tamanho mínimo } \\
\text { da amostra }\end{array}$ & 25 & 31 & 33 & 91 \\
\hline $\begin{array}{l}\text { Reservas } \\
\text { utilizados }\end{array}$ & 9 & 10 & 2 & 21 \\
\hline $\begin{array}{l}\text { Questionários } \\
\text { respondidos }\end{array}$ & 27 & 31 & 34 & 92 \\
\hline
\end{tabular}

Os egressos foram convidados a participar do estudo por contato telefônico e por e-mail, quando eram informados sobre os objetivos e procedimentos da pesquisa. Os questionários foram autoadministrados, enviados por e-mail e pelos Correios. O questionário preenchido era reenviado por e-mail e pelos Correios, com termo de consentimento assinado e/ou autorizado. $\mathrm{O}$ instrumento de coleta de dados abordou os seguintes aspectos: identificação e contatos; estudos após a graduação; atividades profissionais; mercado de trabalho; avaliação do curso de graduação.

Os dados obtidos foram armazenados em um banco de dados, organizado com o aplicativo estatístico SPSS 13.0, de uso corrente nas Ciências Sociais A análise dos dados foi realizada com base nas seguintes questões: características de ingresso e do percurso na graduação; avaliação do curso de graduação; estudos de pós-graduação; exercício profissional e renda mensal; mobilidade social; atividade corporativa; satisfação profissional.

\section{RESULTADOS E DISCUSSÃO}

\section{Características de Ingresso e do Percurso na Graduação}

A maioria dos egressos é do sexo feminino (75\%), mas a proporção de ingresso de homens no curso de Fisioterapia vem aumentando, tendo passado de $18 \%$ para $29,5 \%$ (Gráfico 1). 
Esses grupos se encontram em faixa etária superior à considerada desejável ao ingresso no ensino superior, ou seja, 18 e 19 anos, indicando que grande parte dos alunos prestou mais de um vestibular, que poderá ter sido para o próprio curso ou para outros cursos. Se analisarmos a idade média dos egressos por estrato, sem considerarmos o sexo, observamos um ligeiro aumento na média de idade: de 19,3 anos para 19,7 anos.

\section{GRÁFICO 1}

Idade de Ingresso na Graduação versus Sexo

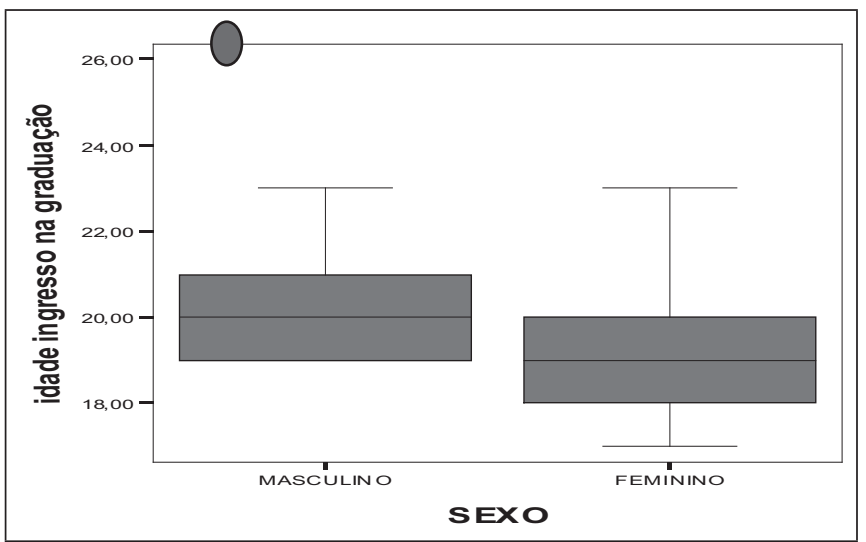

A maior parte dos entrevistados $(62,2 \%)$ cursou a escola média na rede privada. O Gráfico 2 indica que houve diminuição na percentagem dos alunos que estudaram em escola pública, sendo esta percentagem ainda maior que em outros cursos da área de saúde 5 . O percentual de alunos da UFMG que estudou em escola particular é superior ao de alunos que estudou em escolas públicas - 59,3\% e 40,7\%, respectivamente -, bastante próximo do percentual do curso de Fisioterapia ${ }^{6}$

GRÁFICO 2

Respostas do Questionário à Questão: Estudou o Curso Médio em Escola Pública ou Privada?

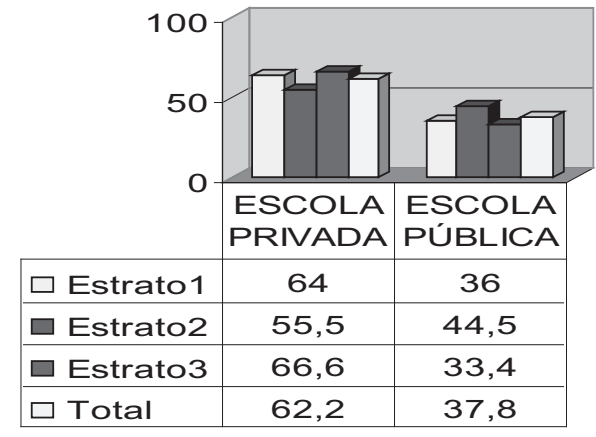

Estudos realizados por Gouveia ${ }^{7}$, Braga et al. ${ }^{5}$ e Borges e Carnielle $^{8}$ afirmam que no ensino superior, em especial nas instituições públicas, existe uma relação entre o segmento social do candidato e o curso pretendido. Borges e Carnielle ${ }^{8}$ observaram que, de maneira geral, os alunos originários de famílias de classe média alta estão inseridos nos cursos de maior prestígio e/ou tradicionais, que dão acesso às carreiras mais valorizadas socialmente, nas quais a renda média auferida é elevada. Já os alunos oriundos de família com baixo poder aquisitivo, em sua maioria, optam por cursos cuja relação candidato/vaga é menor. Percebe-se uma tendência à elitização decréscimo de alunos da escola pública. Pode-se dizer, ainda, que a maioria dos entrevistados cujos pais têm curso superior está no Estrato 3 (quase 57\%), o que confirma essa tendência à elitização.

Apenas 7,6\% da amostra cursaram outra graduação. No entanto, observa-se que a maioria dos que cursaram outra graduação relata que suas atividades profissionais estão vinculadas à Fisioterapia.

\section{Avaliação do Curso de Graduação}

É interessante observar que não houve diferença significativa de respostas entre os estratos na avaliação do currículo (Gráfico 3). Isto indica que o curso de graduação em Fisioterapia da UFMG apresenta algumas características relativas ao currículo que, na percepção dos egressos, se mantiveram constantes, independentemente do período avaliado.

GRÁFICO 3

Avaliação do Currículo

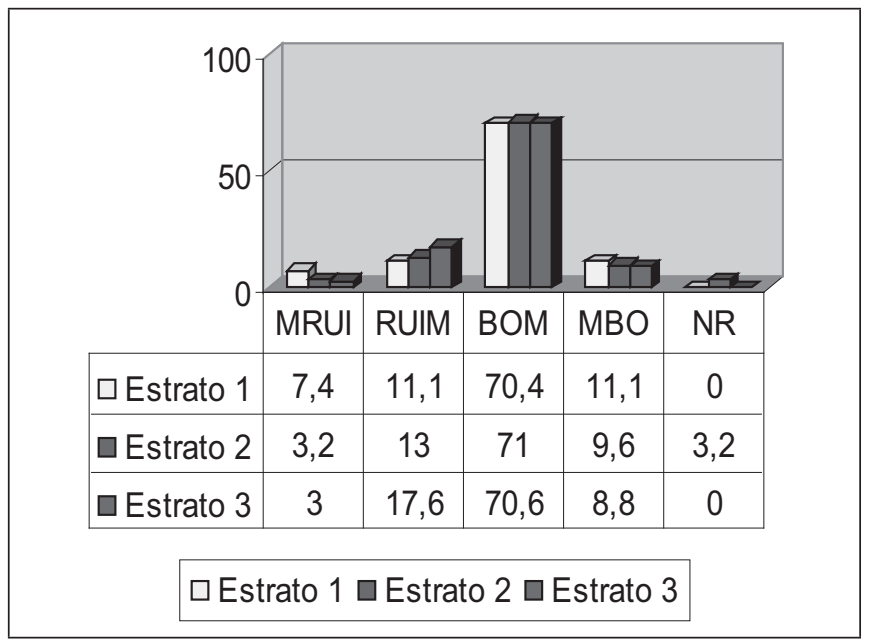

O Gráfico 3 demonstra que o currículo do curso foi avaliado como bom pela maioria dos entrevistados. No entanto, essa avaliação diverge da realizada em 1999 pela Comissão 
de Avaliação Externa (Pauib/UFMG), que, em seu parecer sobre o currículo, implementado em 1986 (segunda versão), ainda em vigor, registrou várias falhas, destacando-se: impossibilidade de identificar os objetivos do curso; indefinição de um perfil profissional; ausência de áreas fundamentais e com grande receptividade no mercado de trabalho, como hidroterapia e fisioterapia esportiva; inadequação do conteúdo programático do ciclo básico ao do ciclo profissional; falta de integração interdisciplinar tanto dos conteúdos como dos programas das disciplinas; má distribuição da carga horária. Essa diferença na avaliação pode ser um indicativo de que os egressos, ao avaliarem o item currículo, na verdade avaliam o currículo "vivido", ou seja, aquele denominado currículo em ação ou real, que envolve todos os tipos de aprendizagem realizados no curso ou sob a supervisão deste, não se limitando à avaliação dos conteúdos programáticos das diferentes disciplinas.

Por um lado, a avaliação do currículo do curso parece mostrar também que as mudanças curriculares não modificaram substancialmente o curso. Isto pode significar que grande parte das transformações formais ou oficiais não causou o impacto previsto, uma vez que não tem o poder de alterar por si só a prática docente. Indica também que a maior qualificação do corpo docente, a partir de 1999, não teve ainda forte repercussão no currículo do curso de graduação, na percepção dos egressos até 2005. Por outro lado, a representação social da UFMG como uma boa universidade talvez leve os alunos, de forma comparativa (considerando os outros cursos existentes na área), a classificar o currículo do curso como bom. Chama a atenção o fato de a avaliação do currículo alcançar mais de $20 \%$ nos itens ruim e muito ruim no Estrato 3 (índice mais alto que nos Estratos 1 e 2), uma vez que os alunos desse estrato fizeram o curso com um corpo docente mais qualificado, com o mesmo projeto pedagógico, que não sofreu grandes modificações desde 1986, e que não mais atende à formação do perfil profissional do fisioterapeuta, prevista nas diretrizes curriculares e demandada pelo mercado de trabalho.

As instalações físicas, a biblioteca e os equipamentos foram avaliados e classificados entre muito ruim e ruim pelos egressos do Estrato 2. Esse estrato corresponde aos alunos que estudaram durante o período caracterizado como a reestruturação do curso, situado entre 1990 e 1997, quando o curso foi ofertado em locais improvisados e com infraestrutura muito precária. Observa-se que houve melhor avaliação pelos egressos do Estrato 3 nos três itens. A transferência do curso para a sede definitiva, a reforma e ampliação da biblioteca da EEFFTO e a aquisição de novos equipamentos para os laboratórios da graduação realizada em 2005 certamente modificarão em curto prazo a avaliação destes itens pelos futuros egressos.

A relação escola versus mercado de trabalho é avaliada entre ruim e muito ruim por todos os estratos, como demonstrado no Gráfico 4. A concentração da vivência profissional somente no final do curso, aspecto já apontado pela avaliação institucional, confirma que o curso oferece pouco contato dos alunos com o mercado de trabalho, concentrando a prática profissional em disciplinas clínicas, desenvolvidas sob orientação docente direta.

\section{GRÁFICO 4}

Avaliação da Relação Escola versus Mercado de Trabalho

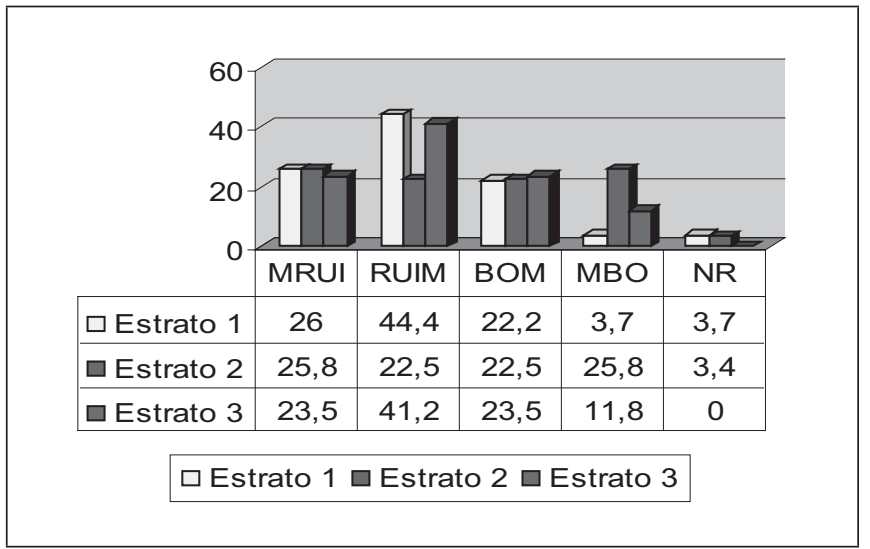

Observa-se, também, que os egressos do Estrato 2 fazem uma avaliação diferente da dos demais estratos: 48,3\% deles avaliam a relação escola versus mercado de trabalho como boa e muito boa. Nesse período, o curso era ministrado por professores especialistas/clínicos, recém-contratados pelo Departamento, o que, provavelmente, aproximou do mercado de trabalho o conteúdo ministrado nas disciplinas do curso. $\mathrm{O}$ estágio curricular também foi mais bem avaliado pelo Estrato 2 (90,5\%), o que também pode ter contribuído para uma melhor avaliação da relação do curso com o mercado de trabalho por esse estrato.

A relação professor/aluno foi bem avaliada em todos os estratos (entre boa e muito boa), sendo observada melhor avaliação no último estrato. O corpo docente foi avaliado positivamente, como competente, pela maioria dos egressos $(86 \%)$. A competência avaliada pelos egressos, porém, parece não estar diretamente ligada à qualificação do corpo docente, pois o aumento da titulação dos docentes nos últimos anos não se traduz na avaliação dos alunos no que se refere à competência. A dedicação e o interesse do corpo docente foram avaliados positivamente por $76,5 \%$ no Estrato 3 . 
Comparando-se os Estratos 3 e 1 (81,5\%), verifica-se que a dedicação e o interesse decrescem ligeiramente, enquanto o bom relacionamento com alunos cresce no Estrato 3. Esses dados sugerem que os alunos fazem distinção entre "relação professor-aluno" e "dedicação e interesse". Considerando a avaliação dos alunos, é possível dizer que o processo de seleção e admissão dos docentes do curso tem sido bastante satisfatório, uma vez que vem recrutando professores considerados competentes por aqueles que sofrem diretamente a consequência desse item na sua formação. Constata-se que o item "competência" é mais bem avaliado que "dedicação e interesse", evidenciando a necessidade de melhorar o investimento docente no curso de graduação. É importante também considerar que as respostas a esses itens (que avaliam os docentes) podem ser consideradas de baixo índice de fidedignidade ou confiabilidade, podendo indicar que os ex-alunos queriam manter boas relações com seus professores, uma vez que o questionário foi produzido na UFMG.

É interessante observar que também não houve diferença significativa de respostas entre os estratos em aspectos referentes à formação básica. No que diz respeito à formação técnica no núcleo específico do curso de graduação há uma melhora, de acordo com as respostas do Estrato 3, indicando que o curso parece ter conseguido melhor equilíbrio entre formação básica e técnica.

\section{GRÁFICO 5}

Respostas do Questionário à Questão:

Como Avalia a Formação Básica do Curso no Instituto de Ciências Biológicas (ICB)?

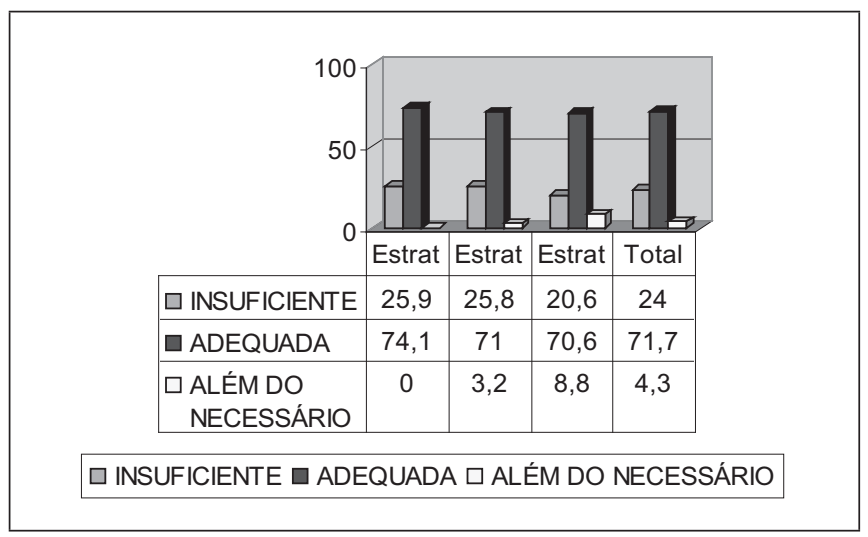

O Gráfico 6 mostra que a formação técnica no núcleo específico da Fisioterapia foi avaliada por 56,5\% como adequada, enquanto a formação básica no ICB foi avaliada como adequada por $71,7 \%$ dos egressos (Gráfico 5). Isto mostra que a formação técnica do núcleo específico precisa ser mais estru- turada, estabelecendo melhor conexão entre teoria e prática, e destas com a realidade do mercado de trabalho. Ao lado disso, por um lado, é preciso considerar que os estudos no campo do currículo mostram que os estudantes tendem a valorizar mais as disciplinas teóricas, em que predominam conceitos abstratos e que discriminam com mais clareza alunos fortes e fracos. Nesse sentido, talvez as matérias do curso básico no ICB sejam mais compatíveis com este perfil, o que levaria os egressos a dizer que a formação básica foi mais adequada. Por outro lado, com as rápidas transformações do mercado de trabalho, pode ser que o conhecimento do curso básico é que possibilite ao estudante uma adaptação mais rápida às novas práticas e novos campos de trabalho.

\section{GrÁfico 6}

Respostas do Questionário à Questão: Como Avalia a Formação Técnica no Núcleo Específico do Curso?

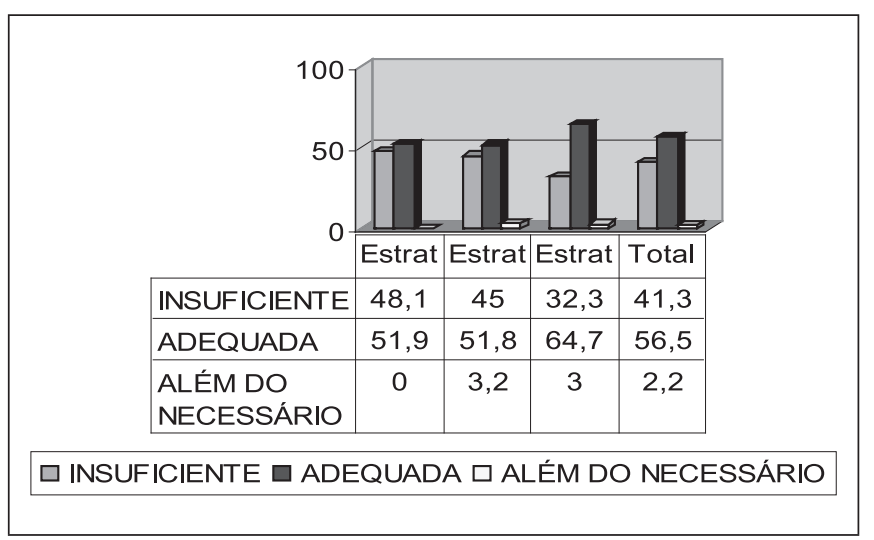

Os egressos avaliam que o curso ajudou pouco e/ou nada a desenvolver iniciativa, criatividade, capacidade de liderança e capacidade de tomar decisões. Estas habilidades foram também reconhecidas como importantes na obtenção de emprego e para um bom exercício profissional. Ao mesmo tempo, avaliam que o curso desenvolveu muito a disciplina, a capacidade de se adaptar às mudanças, a capacidade de trabalhar em equipe e o comportamento ético. A única característica considerada como contribuição para obter emprego ou bom exercício profissional que mostrou diferença estatisticamente significante entre os estratos ( $p$-valor $<0,05$ ) foi a capacidade de liderança. O percentual de pessoas que considera a capacidade de liderança como uma contribuição para obter emprego ou bom exercício profissional foi maior no Estrato 2 (44\%) e menor no Estrato 1 (25\%).

Estes dados caracterizam um curso de práticas pedagógicas tradicionais, pouco flexível e com pouca vivência prática, 
TABELA 2

Nível de Pós-graduação dos Egressos

\begin{tabular}{|c|c|c|c|c|c|c|c|c|c|}
\hline \multirow{2}{*}{ Estratc } & & \multicolumn{7}{|c|}{ Nível de Pós-graduação } & \multirow{2}{*}{$\begin{array}{c}\text { Total } \\
(\%)\end{array}$} \\
\hline & & $\begin{array}{c}\text { Espec. } \\
(\%)\end{array}$ & $\begin{array}{l}\text { Mestrado } \\
(\%)\end{array}$ & $\begin{array}{c}\text { Doutorado } \\
(\%)\end{array}$ & $\begin{array}{c}\text { Esp. + Mestr. } \\
(\%)\end{array}$ & $\begin{array}{c}\text { Esp. + Mestr.+ Dout. } \\
(\%)\end{array}$ & $\begin{array}{c}\text { Mestr. + Dout. } \\
(\%)\end{array}$ & $\begin{array}{l}\text { NA } \\
(\%)\end{array}$ & \\
\hline & 1 & 37,0 & 0 & 0 & 29,6 & 0 & 0 & 33,4 & 100 \\
\hline & 2 & 51,6 & 6,4 & 0 & 22,6 & 3,2 & 3,2 & 13 & 100 \\
\hline & 3 & 44,1 & 6 & 2,9 & 17,6 & 0 & 0 & 29,4 & 100 \\
\hline Total & & 44,6 & 4,3 & 1,1 & 22,8 & 1,1 & 1,1 & 25 & 100 \\
\hline
\end{tabular}

no qual o aluno é "conduzido" durante todo o percurso acadêmico, sem espaço para produzir o próprio percurso e sem possibilidade de inserção na realidade da futura prática profissional. Esse é um aspecto que deverá ser reavaliado pela Coordenação atual do curso, pois, de acordo com as diretrizes curriculares, as habilidades acima avaliadas como pouco desenvolvidas no curso de graduação deverão ser estimuladas e fazem parte do perfil esperado dos egressos dos cursos de graduação, principalmente da área da saúde. A adoção de metodologias ativas e a inclusão do aluno no serviço mais cedo talvez possam facilitar o desenvolvimento dessas habilidades nos profissionais em formação.

\section{Estudos de Pós-graduação}

Os estudos de pós-graduação (especialização, mestrado e doutorado) foram realizados pela maioria dos egressos. É interessante observar que $83,8 \%$ do Estrato 2 realizaram estudos de pós-graduação, ao lado de apenas 55,6\% do Estrato 1 e 55,9\% do Estrato 3. Os egressos do Estrato 2 (formados entre 1990 e 1997) se graduaram em um período de grande expansão dos cursos de especialização e início da especialização na UFMG, o que pode explicar o maior investimento desse estrato nesses cursos.

Uma questão interessante é que o tempo entre a conclusão da graduação e a procura pelos estudos de pós-graduação difere em muito entre os estratos. Os egressos do Estrato 3 procuraram imediatamente a continuidade de estudos, com um espaço máximo de quatro anos após a conclusão da graduação, enquanto nos outros estratos esse tempo é maior. As variáveis sobre estudos de pós-graduação que apresentaram diferenças significativas entre os estratos ( $p$-valores $<0,05)$ estão relacionadas à realização dos estudos de pós-graduação stricto sensu e ao tempo de início da pós-graduação. Percebe-se que o percentual de pessoas que realizou algum estudo de pós-graduação está no Estrato 2 (43\%). O Estrato 3 apresen- ta, em média, o menor tempo de início da pós-graduação (1,9 anos), e o Estrato 1 apresenta maior tempo (10,4 anos).

A Tabela 2 mostra a realização de pós-graduação dos egressos, indicando que cerca de 30\% deles já concluíram o mestrado. Essa porcentagem pode ser considerada alta se aliada à porcentagem dos egressos que já fizeram curso de especialização e evidencia um interesse significativo dos fisioterapeutas formados pela UFMG na formação continuada, ou seja, na maior qualificação profissional.

Observa-se que mais de $50 \%$ dos cursos de especialização se concentram nas áreas de ortopedia/esportes e cardiorrespiratório, indicando maior demanda e maior consolidação dessas áreas da Fisioterapia no mercado de trabalho.

A maioria dos egressos cursou a especialização na própria UFMG, e o mesmo é observado em relação ao mestrado $(23,9 \%)$, caracterizando o papel fundamental da UFMG na formação destes profissionais. Antes da oferta do curso de mestrado em Ciências da Reabilitação, em 2003, pelo Departamento de Fisioterapia da UFMG, os egressos procuraram cursos de mestrado nas áreas básicas da saúde, como fisiopatologia experimental, fisiologia cardiovascular, patologia geral e saúde pública, e de áreas afins, como educação, treinamento esportivo e psicologia do desenvolvimento humano, ou no exterior, quando na área da fisioterapia e reabilitação.

Em relação ao doutorado, dos quatro verificados na amostra, um foi realizado na UFMG e os outros três no exterior, nos Estados Unidos. O nível de pós-graduação (especialização, mestrado e/ou doutorado) está significativamente relacionado com a avaliação dos egressos sobre a influência da pós-graduação na inserção profissional.

\section{Exercício Profissional e Renda Mensal}

A maioria dos profissionais se encontrava trabalhando no momento do levantamento, sendo que $86,9 \%$ consideraram ser seu trabalho vinculado à Fisioterapia. Dos egressos da amos- 
tra, 42,4\% informaram trabalhar em mais de um local, sempre vinculado à Fisioterapia. Interessante observar que, quando presente uma atividade secundária, esta também estava vinculada à Fisioterapia (por exemplo, $1^{\underline{a}}$ atividade - docente em instituição de ensino superior; $2^{\underline{a}}$ atividade - fisioterapeuta em hospital público). No Estrato 3, somente 2,9\% declararam estar desempregados. Esses dados sugerem que as possibilidades de trabalho para os graduados em Fisioterapia pela UFMG são bastante elevadas. Convém observar que 78\% dos entrevistados consideraram que o fato de terem se formado na UFMG facilitou sua inserção no mercado de trabalho. Quando a mesma pergunta foi feita em relação aos fatores influência da família/amigos e formação em nível de pós-graduação, os percentuais correspondentes foram $38 \%$ e $53 \%$. Isto indica que o capital social, associado ao aprimoramento profissional, exerce influência na inserção no mercado de trabalho. No entanto, a influência maior, segundo os dados, é atribuída pelos entrevistados à instituição onde realizaram a graduação, reafirmando o prestígio e positiva imagem social da UFMG.

As variáveis sobre atividades profissionais atuais que mostraram diferenças estatisticamente significantes entre os estratos ( $p$-valores $<0,05$ ) foram: estar empregado em setor público, fonte de remuneração, anos de trabalho na instituição e estar procurando emprego.

O percentual de egressos que trabalha no setor público é maior no Estrato 1 (48\%). Além disso, o Estrato 2 possui maior percentual de profissionais no setor de saúde complementar - convênios (60\%). Por fim, o Estrato 3 concentra o maior percentual de pessoas que ainda estão procurando emprego, mesmo relatando que estão em atividade profissional (67\%). Este último dado sugere que o exercício liberal da profissão está em declínio, o que leva os profissionais a buscar outras formas de inserção e de atuação no mercado.

Há flagrante predomínio das instituições de ensino como local de trabalho, que representam $41,3 \%$ da amostra, enquanto na rede pública de saúde se encontram $16,3 \%$, na assistência de saúde privada $23,9 \%$, na Rede Sarah 4,4\%, em clubes e academias $6,5 \%$ e em outros locais diversos $7,6 \%$.

Uma questão interessante é que os egressos do Estrato 3, que possuem menos tempo de formados, também trabalham em instituições de ensino superior. Isto indica que o curso da UFMG serve de referência para outros cursos, uma vez que seus egressos são docentes em cursos de Fisioterapia de diferentes instituições do Estado de Minas Gerais. Os que trabalham na rede pública, além de desenvolverem atividades assistenciais em hospitais, exercem cargos de gestão de políticas públicas no setor da saúde em níveis municipal e estadual.

É importante considerar que a UFMG oferece pequeno número de vagas anuais na graduação em Fisioterapia. Este pode ser um fator de qualidade que aumenta a relação candidato/vaga, uma vez que a demanda por ensino público é grande, em virtude também do alto preço da mensalidade desse curso nas instituições privadas. Até 1997, o curso oferecia 40 vagas anuais e aumentou desde então para 60 vagas. Este número é muito pequeno, perto do que é lançado hoje no mercado por outras 55 instituições de ensino em Minas Gerais.

Os dados revelam que o fisioterapeuta egresso da UFMG mantém uma relação estável com a instituição onde exerce suas atividades profissionais, inclusive os recém-formados, do Estrato 3.

Uma questão interessante é que $85,8 \%$ estão satisfeitos com sua atividade profissional atual, como demonstra a Tabela 3. O nível maior de satisfação é a do Estrato 2, que apresentou também a maior porcentagem de realização de cursos de pós-graduação. Entre os 13\% que não estão satisfeitos, 2,2\% se referem aos que estão desempregados, $4,3 \%$ têm renda média até $\mathrm{R} \$ 1.000,00$, e 6,5\% trabalham na mesma instituição há pelo menos dez anos e têm renda mensal de até R\$ 3000,00. A insatisfação destes últimos pode estar relacionada à falta de planos de carreira ou de um bom plano de cargos e salários nessas instituições. Os que estão na rede pública, por exemplo, relatam que não têm equiparação salarial com os outros pro-

TABELA 3

Satisfação Profissional

\begin{tabular}{|c|c|c|c|c|c|}
\hline & & \multicolumn{3}{|c|}{ Está satisfeito com sua atividade profissional atual? } & \multirow{2}{*}{$\begin{array}{c}\text { Total } \\
(\%)\end{array}$} \\
\hline & & Não (\%) & $\operatorname{Sim}(\%)$ & NR $(\%)$ & \\
\hline & 1 & 18,7 & 81,3 & 0 & 100 \\
\hline \multirow[t]{2}{*}{ Estrato } & 2 & 6,5 & 93,5 & 0 & 100 \\
\hline & 3 & 14,8 & 82,5 & 2,7 & 100 \\
\hline Total & & 13,2 & 85,8 & 1,0 & 100 \\
\hline
\end{tabular}


TABELA 4

Renda Mensal e Experiência Profissional

\begin{tabular}{lcccccccccc}
\hline & $\begin{array}{c}\mathrm{R} \$ 1.000,00 \\
(\%)\end{array}$ & $\begin{array}{c}\mathrm{R} \$ 2.000,00 \\
(\%)\end{array}$ & $\begin{array}{c}\mathrm{R} \$ 3.000,00 \\
(\%)\end{array}$ & $\begin{array}{c}\mathrm{R} \$ 4.000,00 \\
(\%)\end{array}$ & $\begin{array}{c}\mathrm{R} \$ 5.000,00 \\
(\%)\end{array}$ & $\begin{array}{c}\mathrm{R} \$ 6.000,00 \\
(\%)\end{array}$ & $\begin{array}{c}\mathrm{R} \$ 7.000,00 \\
(\%)\end{array}$ & $\begin{array}{c}\text { Acima de } \\
\mathrm{R} \$ 7.000,00 \\
(\%)\end{array}$ & $\begin{array}{c}\mathrm{NR} \\
(\%)\end{array}$ & $\begin{array}{c}\text { Total } \\
(\%)\end{array}$ \\
\hline Estrato 1 & 7,5 & 11 & 18,5 & 18,5 & 11 & 18,5 & 0 & 11 & 4 \\
Estrato 2 & 6,6 & 9,5 & 16 & 16 & 23 & 3,3 & 9,5 & 9,5 & 6,6 & 100 \\
Estrato 3 & 23,78 & 20,81 & 27,02 & 14,59 & 8,64 & 2,97 & 0 & 0 & 2,97 & 100 \\
\hline Total & 13,2 & 14,1 & 20,4 & 16,2 & 14,1 & 7,6 & 3,2 & 6,4 & 4,4 & 100 \\
\hline
\end{tabular}

fissionais da área de saúde de nível superior, mas fazem parte da categoria de técnicos de nível superior.

Mais de $75 \%$ dos entrevistados exercem suas atividades profissionais em Minas Gerais, o que indica o forte vínculo que a UFMG possui com esse Estado. Os que se deslocaram para outros Estados da Federação trabalham em Brasília, em São Paulo, em Vitória (ES) e na cidade do Rio de Janeiro; e os que estão no exterior trabalham nos Estados Unidos e na Austrália.

Para avaliar a interferência de outros fatores na renda dos entrevistados, não se deve esquecer da dependência da remuneração em relação à experiência profissional. A Tabela 4 mostra a renda mensal dos egressos de acordo com os estratos. A variável "valor aproximado da renda individual" mostrou diferenças estatisticamente significativas entre os estratos ( $p$ -valor $=0,003)$.

Somente $13,2 \%$ da amostra acusam renda mensal de até R\$1.000,00, o equivalente a 2,8 salários mínimos (SM) (o valor do SM oficial no Brasil, em 2006, era de R\$ 350,00), valor abaixo do piso salarial do fisioterapeuta, mas equivalente ao rendimento médio real habitualmente recebido pelos trabalhadores nas regiões metropolitanas no Brasil. Os egressos do Estrato 2 registram os maiores valores de renda mensal, ou seja, 45,3\% têm renda mensal igual ou superior a $\mathrm{R} \$ 5.000,00$ (equivalente a 14,3 SM), enquanto no Estrato $140,5 \%$ acusam essa renda. A renda mensal neste estudo se mostra relacionada à experiência profissional, somada à melhor qualificação no mercado. Da mesma forma, "satisfação profissional e renda mensal" parecem afetadas pela qualificação profissional, uma vez que os egressos do Estrato 2 são os que mais procuraram cursos de pós-graduação.

A formação pós-graduada, quer em curso de especialização, quer no mestrado e no doutorado, também tem interferência significativa na remuneração dos entrevistados. Os que concluíram um curso de pós-graduação declararam renda média de R\$4.000,00 (11,4 SM). Quando se examina a interfe- rência da titulação pós-graduada na remuneração dos entrevistados, constata-se que o término da pós-graduação stricto sensu aumenta a renda dos que trabalham no setor privado, principalmente nas instituições de ensino superior. É importante salientar que os graduados que migraram para outros Estados têm, em média, remuneração equivalente à dos que permaneceram em Minas Gerais.

Os egressos foram questionados "se ampliaram o mercado de trabalho" e, de maneira interessante, egressos de todos os estratos declararam que sim. Entre os que responderam sim, encontramos $48,3 \%$ de egressos de escola pública e 32,3\% de escola privada. Esse dado levanta questões sobre as diferenças na formação escolar dos egressos da escola básica pública e da escola privada. Alguns informaram que introduziram tecnologia ou desenvolveram atividades em um novo campo.

Como se sabe, os profissionais acadêmicos não têm influência direta no mercado de trabalho, mas sua produção intelectual dá autoridade científica à profissão e forma a base para as regras organizacionais e para as decisões de trabalho dos praticantes individuais ${ }^{9}$. Verifica-se, então, que o conhecimento produzido na UFMG vem preparando os profissionais para intervir nesse mercado, introduzindo novas tecnologias e ultrapassando fronteiras de atuação.

\section{Mobilidade Social}

Tendo em vista a literatura da Sociologia da Educação, que associa educação e ascensão social, procurou-se verificar se os graduados em Fisioterapia da UFMG estariam em melhor situação socioeconômica no momento da entrevista do que quando ingressaram no curso. Para tanto, solicitou-se aos entrevistados que comparassem sua situação econômica atual com a de sua família à época em que ingressaram no curso de graduação em Fisioterapia, com três opções de resposta: pior, igual e melhor. É importante considerar que a resposta a esse quesito pode estar impregnada de boa margem de subjetividade, em decorrência, por exemplo, do maior acesso da população, nos 
últimos anos, a bens de consumo duráveis e não duráveis. Esse acesso pode interferir na avaliação do entrevistado sobre suas condições econômicas atuais e a de sua família.

O resultado encontrado, demonstrado no Gráfico 7, indica que mais de $60 \%$ dos fisioterapeutas avaliaram sua situação econômica como melhor que a de seus pais, enquanto pouco mais de $10 \%$ a consideraram "pior". A resposta "melhor" é ainda mais frequente entre os egressos da escola média pública $(86,8 \%)$, o que pode evidenciar certa consistência das respostas, uma vez que, de modo geral, a população de mais baixa renda no Brasil é que frequenta a escola pública e, assim, teria maior mobilidade social com a graduação em nível superior. Como seria de esperar, a resposta a esse quesito é influenciada pela renda do entrevistado: quanto maior a renda atual, maior a probabilidade de sua situação econômica ser melhor que a de seus pais. No entanto, excetuados aqueles que declararam rendimentos na faixa de $\mathrm{R} \$ 1.000,00$ (2,8 SM), em todas as faixas de renda a resposta "melhor" atinge cerca de $50 \%$, confirmando a associação entre formação em nível superior e mobilidade social ascendente.

\section{GRÁFICO 7}

Conclusão do $2^{\circ}$ Grau em Escola Pública ou Privada versus Situação Socioeconômica Atual em Comparação à da Família Quando do Ingresso na Faculdade

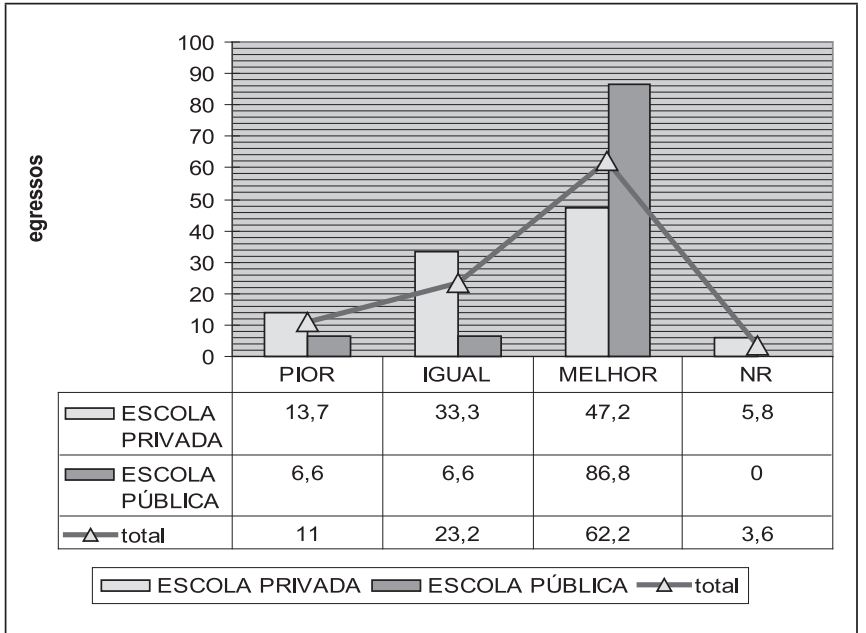

Os dados confirmam a hipótese de que a escola média frequentada - pública ou privada - é um bom indicador da condição socioeconômica do estudante. Os egressos da escola média pública ganham menos que os da escola privada, e aqueles, em maior proporção que estes, consideram sua situação econômica atual melhor que a de seus pais. Este dado mostra a influência do capital social e sua relação com a renda dos pais.
Observa-se que 32,2\% dos egressos da escola média pública trabalham no setor público, enquanto somente 17,6\% dos egressos da escola média privada são funcionários nesse setor, mas estes ocupam cargos de chefia, enquanto os outros desempenham cargos técnicos. O mesmo foi observado em relação aos locais de trabalho, onde os egressos da escola média privada estão em locais de mais difícil acesso ao emprego, como a Rede Sarah, Aeronáutica e instituições federais de ensino superior no Brasil e no exterior. Esta situação pode ser atribuída ao maior capital cultural dos egressos da escola privada, que, geralmente, vêm de família de melhor status sociocultural que os egressos da escola pública. Esses dados evidenciam a relação entre habitus decorrente do pertencimento a determinada classe social, mostrando maior disposição para a liderança entre os egressos provenientes das camadas sociais médias (ex-alunos egressos da escola média na rede privada). Mostram, ainda, a disposição desse segmento social para disputar empregos mais competitivos, o que também pode estar relacionado ao maior capital cultural dos ex-alunos provenientes das camadas médias.

\section{Atividade Corporativa}

Os dados revelam que $56,5 \%$ dos egressos não são associados a nenhuma entidade civil da categoria. Os profissionais do Estrato 1, formados há mais tempo, é que apresentam o maior percentual de associados. Quando questionados sobre "o porquê da não vinculação" a entidades representativas da categoria profissional, os egressos apresentaram justificativas variadas, em geral ligadas à pouca informação sobre o papel, importância e obrigatoriedade de participação nas mesmas, como determina o código de ética da profissão. As respostas registram pouca confiança nas associações e em sua eficiência.

A maioria dos egressos considerou insuficiente a formação ética e política no curso de graduação (Tabela 5). Esse aspecto deve estar relacionado ao fato de essa formação no interior do curso estar bastante limitada às aulas de Fundamentos de Fisioterapia e à disciplina de Ética e Deontologia. Este dado poderia explicar o descompromisso do egresso com sua categoria, fragilizando em muito a identidade profissional no mercado de trabalho.

No entanto, pode-se observar que houve melhor avaliação da formação ética e política do profissional no Estrato 3. Este dado pode estar relacionado com a oferta das disciplinas das Ciências Humanas e também com o contexto histórico e político do País e da profissão. Esta geração tem mais liberdade de discussão política. 
TABela 5

Formação Ética e Política do Profissional na Graduação

\begin{tabular}{llccc}
\hline & & $\begin{array}{c}\text { Insuficiente } \\
(\%)\end{array}$ & $\begin{array}{c}\text { Adequada } \\
(\%)\end{array}$ & $\begin{array}{c}\text { Além do necessário } \\
(\%)\end{array}$ \\
\hline \multirow{3}{*}{ Estrato } & 1 & 70,3 & 26 & 3,71 \\
& 2 & 70,9 & 25,8 & 3,3 \\
& 3 & 61,7 & 38,3 & 0 \\
\hline Total & & 67,3 & 30,4 & 100 \\
\hline
\end{tabular}

A formação nas disciplinas de Antropologia, Sociologia e Administração foi avaliada como insuficiente por $76,1 \%$ dos egressos, adequada por $19,6 \%$ e além do necessário por $4,3 \%$. Estes dados indicam um curso fechado em sua área específica, deixando a desejar na área de Ciências Humanas, Sociais e gerenciais, tão necessária ao exercício profissional.

As associações profissionais são fundamentais para estabelecer a identidade e o perfil corporativo da profissão ${ }^{10}$. Além disto, contribuem para que as profissões se tornem comunidades com identidade, compromisso pessoal, interesses específicos e lealdade corporativa, permitindo que conquistem, assim, prestígio junto à clientela ${ }^{11}$. Nesse sentido, considera-se que a formação ética e política deve ser transversal, sendo observada em todas as atividades do curso de graduação, uma vez que este é responsável pela formação de futuros profissionais para o mercado de trabalho.

\section{Satisfação profissional}

Em dois momentos do questionário os fisioterapeutas foram solicitados a dar informações sobre sua satisfação com o exercício profissional. No primeiro deles, perguntou-se "se estavam satisfeitos com sua atividade atual", tendo como opções de resposta sim e não. Os egressos estão satisfeitos $(85,9 \%)$ com suas atividades profissionais vinculadas à fisioterapia. No segundo momento, perguntou-se "se vale a pena ser fisioterapeuta", com as opções de resposta sim, mais ou menos e não. A Tabela 6 indica que $66,3 \%$ dos egressos avaliam que vale a pena ser fisioterapeuta. No entanto, apenas 53\% dos egressos do Estrato 3 fazem a mesma avaliação.

Essa tendência no último estrato provavelmente se deve às mudanças no mercado de trabalho, agora mais competitivo e com cenário socioeconômico diferente, com alterações profundas nas relações de trabalho. Por um lado, hoje a atuação no setor privado e de saúde complementar está sujeita às empresas de planos de saúde e às disputas de mercado entre médicos e outros profissionais da saúde. Por outro, no setor público da área da saúde, ainda não foram estabelecidos postos de trabalho e cargos em número suficiente e adequado para o profissional fisioterapeuta.

A remuneração parece produzir efeitos sobre o grau de satisfação com a atividade exercida. Entre os 6,5\% insatisfeitos, 50\% têm renda média de até $\mathrm{R} \$ 1.000,00$ (2,8 SM), 17\% registram renda de até $\mathrm{R} \$ 2.000,00$ (5,6 SM), e os 33\% restantes declararam renda média de $\mathrm{R} \$ 4.000,00$ (11,4 SM). Para estes últimos, é possível que a insatisfação seja afetada por outros fatores além da remuneração. Esses dados indicam que ainda é alta a satisfação com a profissão e que as dificuldades no exercício profissional não diminuem o nível de satisfação com a profissão.

TABELA 6

Vale a pena ser fisioterapeuta?

\begin{tabular}{|c|c|c|c|c|c|}
\hline & & \multicolumn{3}{|c|}{ Vale a pena ser fisioterapeuta? } & \multirow{2}{*}{$\begin{array}{c}\text { Total } \\
(\%)\end{array}$} \\
\hline & & $\begin{array}{l}\text { Não } \\
(\%)\end{array}$ & $\begin{array}{c}\text { Mais ou menos } \\
(\%)\end{array}$ & $\begin{array}{l}\text { Sim } \\
(\%)\end{array}$ & \\
\hline \multirow{3}{*}{ Estrato } & 1 & 3,7 & 25,9 & 70,4 & 100 \\
\hline & 2 & 0 & 22,6 & 77,4 & 100 \\
\hline & 3 & 14,7 & 32,3 & 53 & 100 \\
\hline Total & & 6,5 & 27,2 & 66,3 & 100 \\
\hline
\end{tabular}




\section{CONCLUINDO O ESTUDO}

Este estudo forneceu elementos para a análise do processo de formação profissional do egresso da UFMG e sua inserção no mercado de trabalho. Algumas das questões identificadas constituem um campo fértil para análises futuras.

\section{Contribuição para o Processo de Profissionalização da Fisioterapia}

O curso de Fisioterapia da UFMG vem ampliando suas atividades e investindo maciçamente na qualificação de seu corpo docente. O conhecimento produzido pelo Departamento de Fisioterapia foi um elemento definidor da profissão em Minas Gerais e no Brasil. Esse conhecimento aplicado nos cursos de graduação e pós-graduação certamente introduziu tecnologia no mercado de trabalho e conquistou autoridade científica profissional na área. Dessa forma, o curso não só alcançou seu objetivo inicial, como teve importante participação na construção da identidade da profissão em Minas Gerais. Teve impacto na representação interna e externa ao grupo, ampliando e delimitando fronteiras do campo de atuação.

A competição para ingressar no curso e a conquista de sua autoridade científica traduzem o reconhecimento acadêmico e o prestígio alcançados perante a clientela e a sociedade, aproximando a profissão da proteção do Estado e facilitando, dessa forma, a conquista da jurisdição exclusiva. Abott ${ }^{12}$ afirma que é o nível abstrato do conhecimento profissional que diferencia a competição interprofissional da competição entre as ocupações em geral.

A estrutura profissional de uma sociedade é extremamente dinâmica, e neste estudo foram identificados alguns sinais que indicam um deslocamento ascendente da fisioterapia. Ela nasceu como uma profissão assalariada, com predomínio do gênero feminino, subordinada à autoridade médica masculina e sem uma definição clara de campo de atuação. Hoje, apresenta alguns aspectos semelhantes aos de outras profissões que se caracterizam pelo exercício autônomo, como a medicina, a odontologia e o direito, deixando também de ser uma profissão predominantemente feminina. Fortaleceu-se, definindo sua área de atuação, abrindo novas áreas funcionais na divisão do trabalho profissional e consolidando seu controle interno e externo.

Pode-se dizer que hoje o Departamento de Fisioterapia tem uma importância significativa para a profissão em Minas Gerais e no Brasil, uma vez que se volta para a formação acadêmica do profissional, desde a graduação até o doutorado. Isto significa uma produção acadêmica de relevância internacional, contribuindo para a conquista da excelência acadêmi- ca. Os profissionais formados por esse curso têm contribuído para inovações no campo do trabalho, introduzindo novas tecnologias e novas formas de atuação.

Os profissionais se estabelecem e sustentam seus lugares no mercado de trabalho diferenciando-se em praticantes (clínicos), administradores e intelectuais. Atualmente, já é evidente essa divisão entre os fisioterapeutas.

Neste estudo, identificou-se que os egressos da UFMG, em Minas Gerais, tendem a se estabelecer como intelectuais e administradores da profissão. Mesmo não se tendo investido diretamente no desenvolvimento das associações profissionais e embora os egressos tenham avaliado a formação ética e política como insuficiente no curso, constatou-se que muitas das entidades civis atuantes contam com a participação ativa dos egressos do curso. O envolvimento dos profissionais com associações ou outros órgãos de representação deve ser valorizado e estimulado pelos docentes para que a profissão alcance melhor status social. Ao lado disso, é importante considerar que a capacidade de cooperação entre colegas é fundamental nos aspectos constitutivos de uma profissão.

A profissionalização da fisioterapia depende das atitudes e do comportamento profissional dos fisioterapeutas, bem como do grau de aceitação dessas atitudes e comportamento pelo público. É importante que docentes dos cursos de Fisioterapia e administradores da categoria profissional estejam atentos aos elementos que contribuem para a profissionalização e que apoiem as mudanças necessárias para expandir a atuação dos profissionais e a diferenciação dos papéis desempenhados por outros profissionais da área da saúde.

\section{O Curso de Graduação e o Fisioterapeuta Formado na UFMG}

Mesmo tendo forte impacto no processo de profissionalização da fisioterapia, a qualificação do perfil docente do Departamento de Fisioterapia da UFMG não se apresentou como elemento significativo na avaliação dos egressos do curso de graduação. O curso permanece estruturado conforme o modelo da racionalidade técnica, em que a atividade profissional consiste na aplicação de conhecimentos e de técnicas derivadas do conhecimento científico ${ }^{13}$, uma vez que se estrutura em dois blocos: disciplinas de fundamentação, seguidas de um conjunto de disciplinas profissionalizantes, com atividades práticas nos períodos finais do curso. Apesar dos limites desse modelo o curso conquistou autoridade técnica e científica, principalmente na década de 1990, assumindo uma formação predominantemente crítica quanto ao emprego de técnicas.

Segundo a percepção dos egressos, o curso apresenta bom currículo e boa relação professor-aluno, mas é ruim no que se re- 
fere à relação entre a escola e o mercado de trabalho. Esses dados caracterizam um curso mais teórico, com pouca vivência prática.

Grande parte das transformações formais ou oficiais que ocorreu no curso desde a sua criação, não parece ter causado o impacto previsto, uma vez que tais reformas não têm o poder de alterar, por si sós, a prática dos docentes. As práticas pedagógicas tradicionais prevalecem ainda no cenário de ensino-aprendizagem do curso. Tal aspecto deverá ser reavaliado pela Coordenação atual do curso, pois, de acordo com as diretrizes curriculares, as habilidades acima avaliadas como pouco desenvolvidas no curso de graduação deverão ser estimuladas e fazem parte do perfil esperado dos egressos dos cursos de graduação, principalmente da área da saúde. A adoção de metodologias ativas e a inclusão do aluno mais cedo em atividades do campo profissional talvez possam facilitar o desenvolvimento dessas habilidades nos profissionais em formação.

A avaliação do corpo docente é um indicativo da eficiência do processo de seleção e admissão dos docentes, ao mesmo tempo em que indica a necessidade de um pouco mais de envolvimento dos docentes com o curso de graduação modelo.

No estudo, identificou-se que a maioria dos profissionais formados na UFMG é do sexo feminino, com idade média de 34 anos, tendo cursado a pós-graduação em níveis de especialização e/ou mestrado, trabalhando grande parte em instituições de ensino superior e em funções de gestão no serviço público e no setor privado. Os demais egressos do curso trabalham em hospitais, clínicas, academias e domicílios, atuando principalmente na reabilitação. As ações na Atenção Primária estão concentradas nas atividades dos que exercem a docência, fortalecendo a importância das universidades e faculdades no desenvolvimento de novas tecnologias na Atenção Primária e treinamento para a atuação profissional.

O egresso do curso de graduação em Fisioterapia da UFMG está inserido no mercado de trabalho, satisfeito com sua atividade profissional e reconhece que introduz novas técnicas e formas de atuação nesse mercado. Praticamente todos trabalham em atividades relacionadas com a fisioterapia, acham que vale a pena ser fisioterapeuta e acusam um salário médio de $\mathrm{R} \$ 3.600,00$. Os dados sugerem que as possibilidades de trabalho para os graduados em Fisioterapia pela UFMG são bastante elevadas.

Este estudo identificou que os profissionais formados na década de 1990 apresentam características que merecem ser analisadas com maior profundidade em estudos posteriores.

\section{CONSIDERAÇÕES FINAIS}

Com base nos dados deste estudo, podemos concluir que o curso de graduação em Fisioterapia da UFMG está bem con- solidado, o que é evidenciado pela qualificação dos docentes que nele lecionam; pela melhoria de sua infraestrutura; pelo processo de inserção de seus egressos no mercado de trabalho; e pela avaliação bastante positiva que fazem do curso, entre outros aspectos.

No entanto, a estrutura atual do curso está sendo desafiada pelas novas propostas no campo da saúde, que exigem reformas nos cursos de graduação nessa área. Essas novas propostas valorizam a integração de práticas profissionais e consideram o ser humano como uma totalidade que sofre influências do ambiente em que vive e que necessita de cuidados para manter sua saúde.

Nesse contexto, o curso de Fisioterapia alcançará novo patamar de desenvolvimento uma vez que consiga superar a organização curricular, criando espaços interdisciplinares; quando for capaz de iniciar os estudantes, desde o princípio do curso, em atividades práticas presentes no campo profissional e principalmente com ações na Atenção Primária; no momento em que introduzir novas formas de ensino e de avaliação que considerem o estudante como sujeito ativo no processo de aprendizagem, ou seja, novas práticas pedagógicas. Tais medidas poderão levar à formação de um fisioterapeuta mais autônomo e criativo, mais competente para enfrentar as rotineiras e as complexas situações da vida profissional.

\section{REFERÊNCIAS}

1. Amorim A, Souza SMZL. Avaliação institucional: definições e posicionamentos. Estudo Aval Educacional. 1990;(1):9-12.

2. Meira MDD, Kurcgant P. Avaliação de curso de graduação segundo egressos. Rev Esc Enferm [periódico na Internet]. 2009; 43(2): [acesso em 13 dez. 2009]. Disponível em Http:/ / Www.Scielo.Br/Scielo.Php?Script=Sci_Arttext\&Pid=S0080$-62342009000200031 \&$ Lng=En\&Nrm=Iso

3. Câmara AMCS. A formação e a atuação do profissional fisioterapeuta: um estudo com egressos da UFMG - 1982-2005. Belo Horizonte, 2006. 156p. Programa de Pós-Graduação em Educação: Conhecimento e Inclusão Social, da Faculdade de Educação da Universidade Federal de Minas Gerais.

4. Babbie E. Métodos de pesquisas de survey. Tradução de Guilherme Cezarino. Belo Horizonte: Editora UFMG, 1999. 519 P. Título Original: Survey Research Methods.

5. Braga MM, Peixoto MCL, Bogutchi TF. Tendências da demanda pelo ensino superior: estudo de caso da UFMG. Cadernos de Pequisa, São Paulo jul 2001;(113) 129-152.

6. FUMP. Perfil socioeconômico e cultural dos estudantes da graduação da UFMG. Relatório - Belo Horizonte: FUMP/ UFMG, 1997. 
7. Gouveia AJ. Origem social, escolaridade e ocupação. Cadernos de Pesquisa,1980; (32) 3-30.

8. Borges JLG, Carnielli BL. Educação e estratificação social no acesso à universidade pública. Cadernos de Pesquisa, São Paulo jan-abr 2005; 35 (124) 113-139.

9. Bonelli MG, Donatoni S. Os estudos sobre as profissões nas Ciências Sociais brasileiras. Revista Brasileira de Informação Bibliográfica em Ciências Sociais 1996;4(1) 109-142.

10. Wilensky HL. The professionalization of everyone? In: Grusky, Oscar; Miller, George (Org.). The Sociology of Organizations: Basics Studies. New York: The Free Press, 1970.

11. Pereira-Neto AF. Ser médico no Brasil: o presente no passado. Rio de Janeiro: Editora Fiocruz, 2001.

12. Abbott A. The future of professions: occupation and expertise in the age of organization. Research in the Sociology of Organizations 1991; (8)17-42.
13. Schön DA. Educando o profissional reflexivo. Porto Alegre, Artes Médicas Sul, 2000.

\section{CONTRIBUIÇÃO DOS AUTORES}

As autoras do artigo contribuíram de forma significativa na concepção do estudo, análise e interpretação dos dados.

\section{CONFLITO DE INTERESSES}

Declarou não haver.

\section{ENDEREÇO PARA CORRESPONDÊNCIA}

Ana Maria Chagas Sette Câmara

Rua Pratápolis, 85 - apto 301

Grajaú - Belo Horizonte

CEP. 30430-230 - MG

E-mail: anasettecamara@hotmail.com 